\title{
Remote sensing of marine oil spills from airborne platforms using multi-sensor systems
}

\author{
N. Robbe \& T. Hengstermann \\ OPTIMARE Sensorsysteme AG, Germany
}

\begin{abstract}
Airborne oil spill monitoring has become a global concern during the last three decades. Currently there are a multitude of specialized airborne remote sensing systems all over the world, which are operated for this purpose, especially for the deterrence of potential polluters and the support of oil spill clean-up activities. In the 1970s and 1980s the main effort has been directed towards developing sensors with enhanced spill monitoring capabilities which explains the large number of existing well-established oil spill remote sensors like infrared/ultraviolet line scanners, microwave radiometers, laser fluorosensors, and X-band radar systems. Recently, more attention has been paid to the automated processing of remotely sensed oil spill data acquired by airborne multi-sensor platforms in terms of data analysis and fusion. In this paper, we focus on data processing and present ways of improving the usability of airborne multi-sensor oil spill monitoring systems with regard to on-board and ground-based data processing as well as the distribution of remotely sensed oil spill data and derived data products. In this context we (1) give an overview of currently existing oil spill remote sensing technology, (2) present the Multispectral Environmental Data Unit for Surveillance Applications (MEDUSA) for network-based real-time data acquisition, (3) describe a MEDUSA software module for analysis and fusion of multi-sensor data and (4) present the distribution of oil spill data and related data products using web-based geographical information systems (web-based GIS). In particular, the automated generation of thematic maps of the oil spill scene along with their web-based distribution is becoming more important in distributed marine crisis management.
\end{abstract}

Keywords: airborne remote sensing, oil spill, marine pollution, multi-sensor system, data acquisition, data processing, data fusion, geographical information system, marine crisis management. 


\section{Introduction}

Since the beginning of the 1980s a standard suite of sensors for airborne oil spill remote sensing has been established. It consists of a side-looking airborne radar for far-range detection, and an infrared/ultraviolet imaging system, such as an IR/UV line scanner, for near-range monitoring of oil spills. Advanced sensors like laser fluorosensors or microwave radiometers allow measurements of oil film thickness and, with regard to laser fluorosensors, a remote classification of the oil.

The two German maritime surveillance aircraft of Do228-212LM type and the four new Spanish maritime surveillance aircraft, are examples of aircraft which are equipped with all abovementioned sensors; OPTIMARE Sensorsysteme AG, Bremerhaven, Germany, has been engaged by the aircraft manufacturer EADS CASA to equip four aircraft of CASA CN-235 type with maritime surveillance systems. These systems, which are currently being finished (as at spring 2006), will be operated by the Spanish Marine Safety Agency SASEMAR. Acquisition and management of pollution data onboard the Spanish aircraft and the German maritime surveillance aircraft 57+04 (fig. 1) are based on the Multispectral Environmental Data Unit for Surveillance Applications (MEDUSA). The MEDUSA system itself and the benefits that can be derived from it in terms of analysis, fusion and distribution of remote sensing data are described later in this paper.

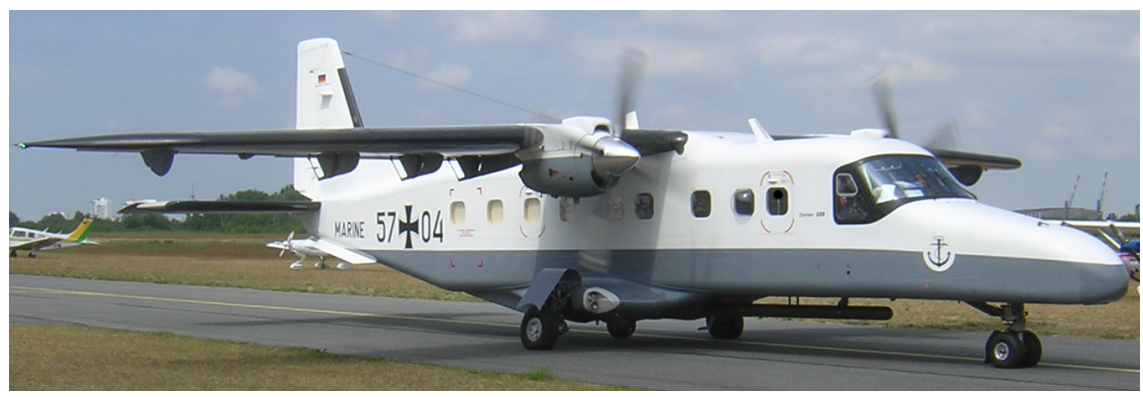

Figure 1: German maritime surveillance aircraft of Do228-212LM type at the regional airport Bremerhaven Luneort, Germany.

\section{Overview of existing oil spill remote sensing technology}

Airborne oil spill remote sensing is usually divided into far-range detection and near-range monitoring. Far-range detection is based on the use of radar systems which usually cover swaths of several tens of kilometers. Suspicious structures detected by airborne radar are then investigated on-site using near-range sensors. Near-range monitoring of oil spills includes visualization, quantification and classification of the type of oil. Most sensor suites operated in the world are at 
least capable of visualizing small-scale structures of oil spills. Examples of nearrange data are shown in fig. 4.

\subsection{Side-looking airborne radar}

Side-looking airborne radar (SLAR) is a standard X-band radar technique for farrange detection of oil spills. At an aircraft altitude of about $300 \mathrm{~m}$ SLAR systems usually have a cross-track swath between $60 \mathrm{~km}$ and $80 \mathrm{~km}$. Oil spill detection using airborne radar is based on the principle that oil spills as well as biogenic slicks or specific hydrodynamic effects may result in a reduction of the radar backscatter signal due to the dampening of surface wave structures. The variety of surface-affecting phenomena implies that this method is vulnerable to false alarms. Assuming a sufficiently large sea surface roughness, airborne radar can be used to discriminate oil spills from the unpolluted sea surface, fig. 2. Microwave remote sensors like the SLAR are all-weather devices: microwaves can penetrate clouds, fog, drizzle and rain.

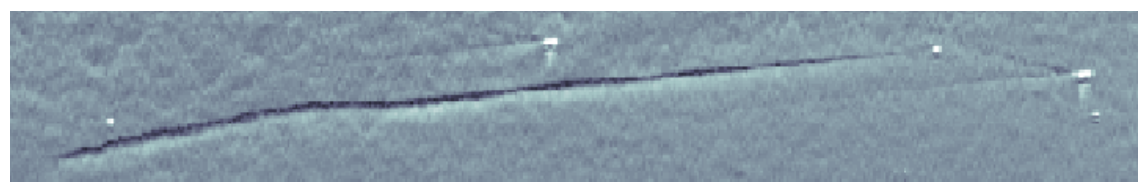

Figure 2: Part of a SLAR image showing an illegal discharge of oil (dark plume behind one of three ships).

\subsection{Infrared/ultraviolet imaging devices}

Infrared/ultraviolet imaging devices like IR/UV line scanners are standard instruments for near-range monitoring of oil spills. These devices are usually sensitive in the thermal infrared $(8 \mu \mathrm{m} \ldots 14 \mu \mathrm{m})$ and the near ultraviolet $(320 \mathrm{~nm}$ $\ldots 380 \mathrm{~nm}$ ). At an aircraft altitude of $300 \mathrm{~m}$ the swath width of a typical IR/UV line scanner amounts to about $500 \mathrm{~m}$.

Films of crude oil on the water surface can be detected in the thermal IR because (1) they have lower integral emissivities than water in this spectral region (Fontanel and Roussel [1]) and (2) they can be heated through absorption of sun light if they are sufficiently thick. Reported values of the minimum detectable oil film thickness in the thermal IR range from $2 \mu \mathrm{m}$ to $70 \mu \mathrm{m}$ (Robbe [2]). Hot spots which are generated through absorption of sun light are assumed to appear in the thickness range between $50 \mu \mathrm{m}$ and $500 \mu \mathrm{m}$.

Near UV remote sensing of oil spills is based on the fact that the air/oil interface of the oil film has about twice the integral near UV reflectance of the unpolluted sea surface. Assuming that sufficient visibility and daylight illumination are given, very thin sheens of oil can be mapped using near UV sensors. The minimum 
detectable oil thickness in this wavelength region amounts to $0.01 \mu \mathrm{m}$ (Fingas [3]). False targets such as biogenic slicks, foam or sun glints may interfere. Recent research work suggests that the UV signal measured above an oil spill can be used for fusion with optical thickness data measured with a laser fluorosensor (Robbe and Zielinski [4]).

Combined IR/UV devices show the areas of intermediate and large oil film thickness as well as the total extent of the oil spill.

\subsection{Microwave radiometer}

Microwave radiometers (MWRs) are passive microwave remote sensors which are used to map oil layers exceeding a thickness of $\sim 50 \mu \mathrm{m}$. Oil spills appear as brighter objects in the microwave region relative to the oil-free sea surface. The reason for this is a positive emissivity difference between oil and water in this wavelength range. Multi-frequency MWRs can be used for measurements of oil film thickness (Ulaby et al [5]). The MWRs which are integrated in the German Do228-212LM surveillance aircraft are capable of measuring oil layer thickness in the range from $\sim 50 \mu \mathrm{m}$ to $\sim 3000 \mu \mathrm{m}$. At an aircraft altitude of $300 \mathrm{~m}$ their swath widths amount to about $500 \mathrm{~m}$. Unlike IR, UV and VIS sensors, MWRs are all-weather sensors (cp. section 2.1).

\subsection{Laser fluorosensor}

Laser fluorosensors (LFSs) for oil spill monitoring are based on high power UV lasers which send short laser pulses $(5 \mathrm{~ns} . . .20 \mathrm{~ns})$ towards the water surface. The laser-induced fluorescence and backscatter are received by a telescope and separated spectrally into a limited number of monochromatic signals. According to several studies, [6-9], the detected discrete emission spectrum can be used to estimate the oil class and to measure the thickness of optically thin surface films of crude and refined oil. Both German maritime surveillance aircraft are equipped with an imaging LFS called Imaging Airborne Laser Fluorosensor (IALFS). At an aircraft altitude of $300 \mathrm{~m}$ its swath width amounts to $\sim 150 \mathrm{~m}$.

\section{Multispectral Environmental Data Unit for Surveillance Applications (MEDUSA)}

The usability of a multi-sensor system for airborne oil spill monitoring depends critically on the underlying data acquisition architecture, especially concerning real-time on-line visualization and reliable data storage. The challenging task is to perform the latter processes in spite of high data rates and several imaging sensors. The Multispectral Environmental Data Unit for Surveillance Applications (MEDUSA) is a data acquisition system which fulfils the abovementioned requirements, fig. 3. Each of the sensors integrated in the MEDUSA network is administrated by an individual sensor processor which (1) digitizes and stores the 
data on an internal buffer, (2) attaches time stamps to the data and (3) transfers the time-referenced data via 1 Gbit fiber optic ethernet cables to the database of the central mission computer. The central mission computer stores the data and provides time information as well as display and operating interfaces. Sensor management, on-line visualization and data analysis is facilitated by a graphical user interface (GUI). Due to redundant data storage on both the sensor processor and the database of the central mission computer a high reliability is achieved.

The MEDUSA concept is also used for data management onboard polar research aircraft. The modification MEDUSA-P is especially designed for operation under extreme environmental conditions such as temperatures down to $-40^{\circ} \mathrm{C}$ and flight altitudes of up to $24000 \mathrm{ft}$ without pressurization (Garbrecht et al [10]). The main conception of MEDUSA can easily be adapted to further applications (Hengstermann et al [11]).

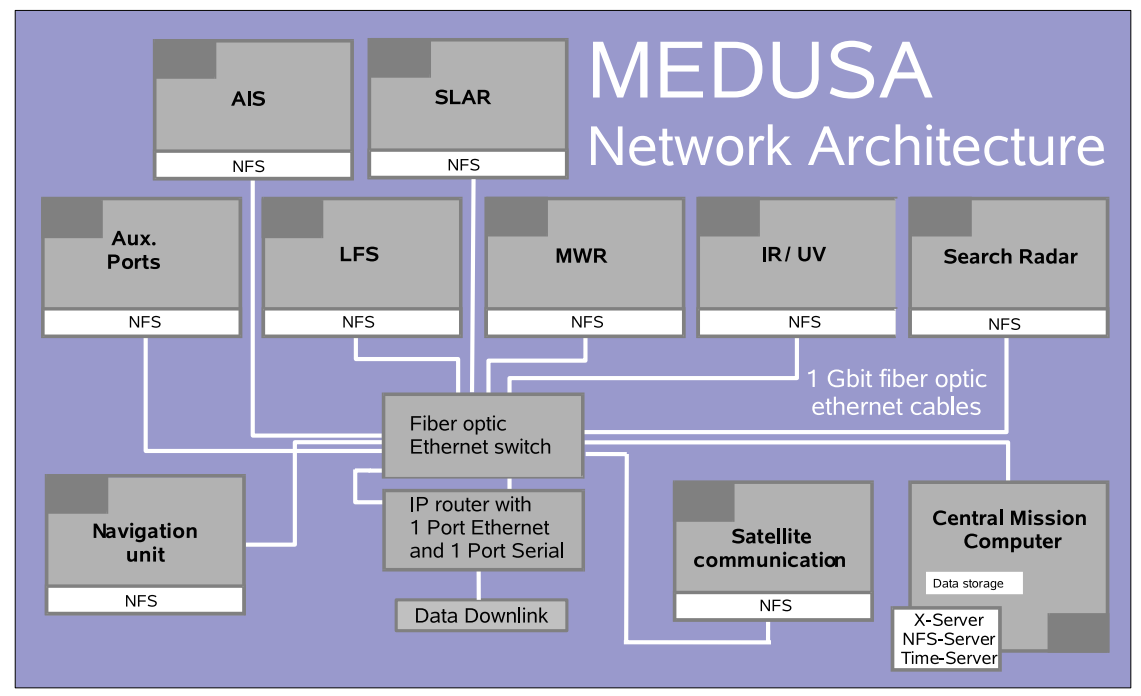

Figure 3: The MEDUSA network architecture for accurate time- and georeferenced acquisition of multi-sensor data. Raw data as well as the information of processed data of marine pollution can be relayed to spill response crews via Data Downlink [12].

\section{MEDUSA software module for analysis and fusion of multi-sensor data}

Robust storage of large amounts of remote sensing and meta data on a central database at high data rates is the key feature of the MEDUSA system. In contrast to traditional systems which only perform visualization and storage of unrectified sensor images the MEDUSA system opens up various opportunities in terms of 
post-processing. Oil spill data that are acquired and internally distributed by the MEDUSA network can be interactively analysed using the MEDUSA software module for oil spill analysis. It is a software package for post-overflight analysis of multi-sensor oil spill data. The software module is based on a graphical user interface (GUI) and on database connectivity, fig. 4. It is installed on the central mission computer and can also be run on mobile and stationary ground processing stations. The main features of this processing system are basic spatial analysis by interactive polygon drawing, volume calculation, oil classification, geo-referencing, and report generation. The calculation of a volume estimate at least requires a thickness sensor like an MWR or an LFS; the latter is the only sensor which is capable of remotely classifying marine oil pollution. Report generation is a semi-interactive procedure. The results of the analysis like e.g. volume estimates and relevant geo-positions are automatically entered in a report template like e.g. the Bonn Agreement Standard Pollution Observation/Detection Log.

Currently, the Oil Spill Scene Analysis System (OSSAS) is being implemented as a subsystem of the software module. It combines automated scene analysis and data fusion. OSSAS uses IR, UV and LFS data to create a thematic map of the oil spill scene (Robbe and Zielinski [4]). The fusion component of OSSAS is based on the calibration of UV data with optical thickness data measured by a laser fluorosensor. An example of a thus-created thematic map of the oil spill scene is shown in fig. 5 .

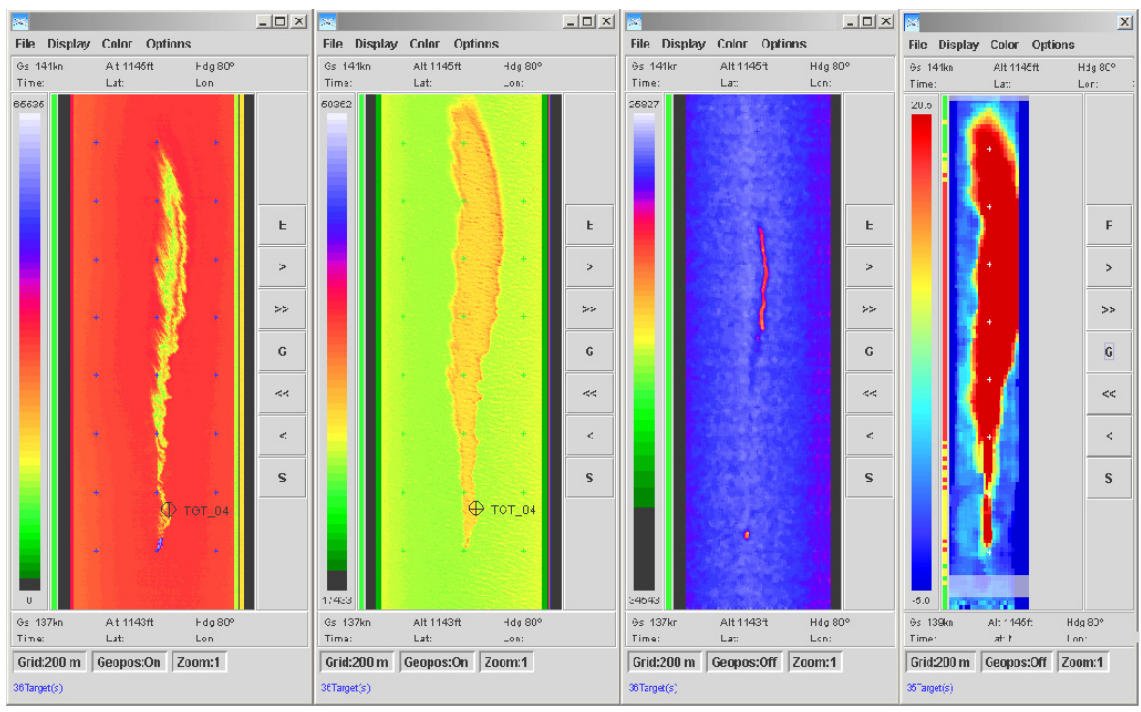

Figure 4: Four windows of the MEDUSA software module for oil spill analysis. From left to right: IR image, UV image, MWR image ( $89 \mathrm{GHz}$ channel) and LFS thickness image of an oil spill (Robbe and Hengstermann [12]). 

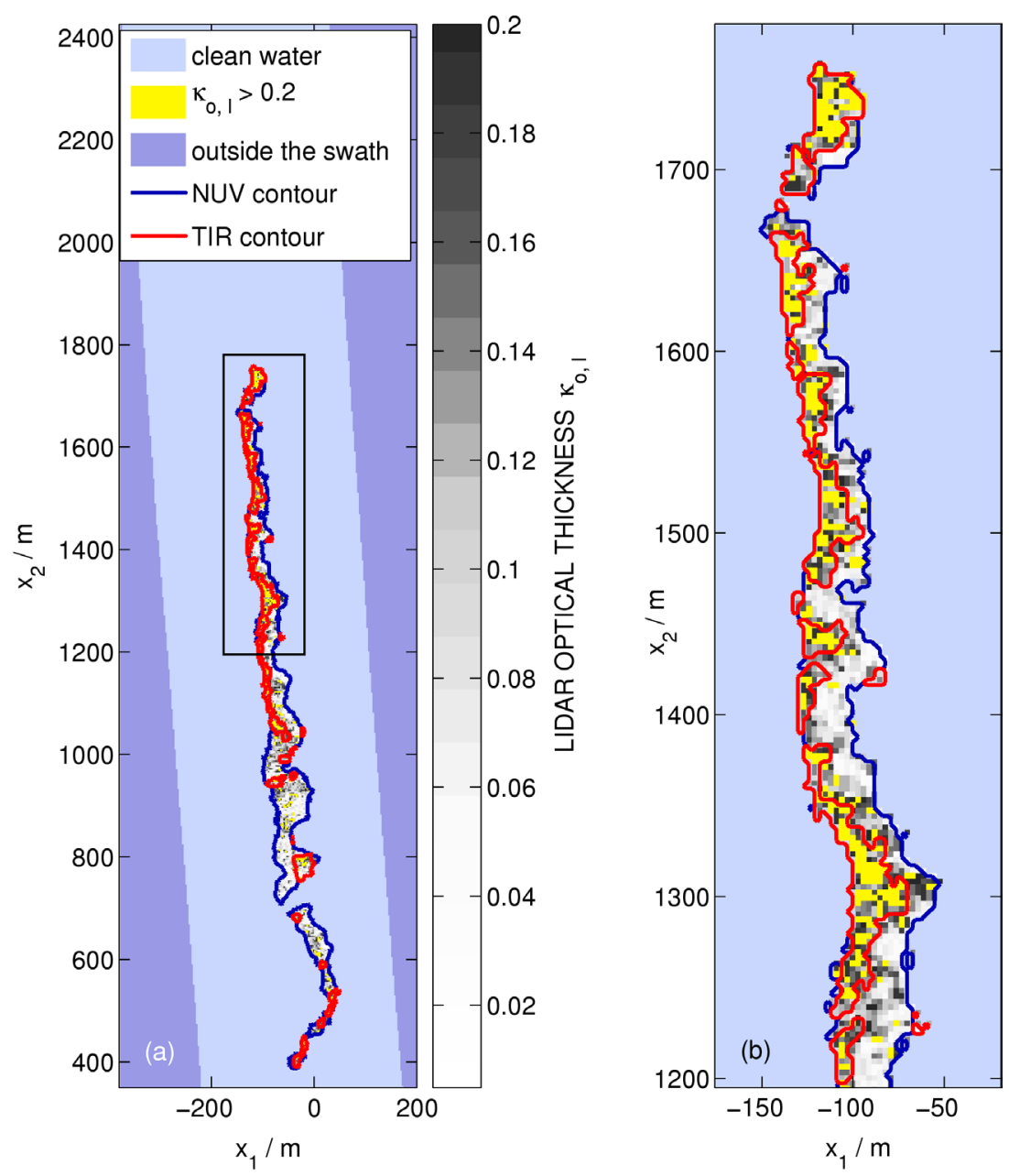

Figure 5: Example of a thematic map of an 'oil wake' (zoomed-out view on the left and magnified view on the right). The fused UV/LFS greyscale image of lidar optical thickness $\kappa_{o, l}$ is overlaid with the extracted thermal IR (TIR) and near UV (NUV) contours (Robbe and Hengstermann [2, 12]).

\section{Web-based geographical information systems in distributed marine crisis management}

The MEDUSA software module for oil spill analysis is capable of exporting georeferenced data products like thematic maps (fig. 5) and sensor data. These and other types of geo-referenced data like e.g. satellite data can be distributed using web-based geographical information systems (web-based GIS), a technique which is becoming more important in distributed marine crisis management. 
The use of web-based GIS technology for visualization of remote sensing data and associated data products is predestinated for oil spill response because it makes pollution information available to all parties involved in the response mechanism. The development of a web-based GIS as a decision support tool for marine monitoring of water quality and pollution had been subject of the European RTD Project DISMAR (Contract No. IST-2001-37657) from 2001 to 2005. Fig. 6 shows an geo-referenced SLAR image displayed on the Web Map Server interface of the DISMAR system. The SLAR image was acquired by one of the German maritime surveillance aircraft over the Meldorf Bight area, Northern German Wadden Sea. The DISPRO system is capable of integrating any type of georeferenced information.

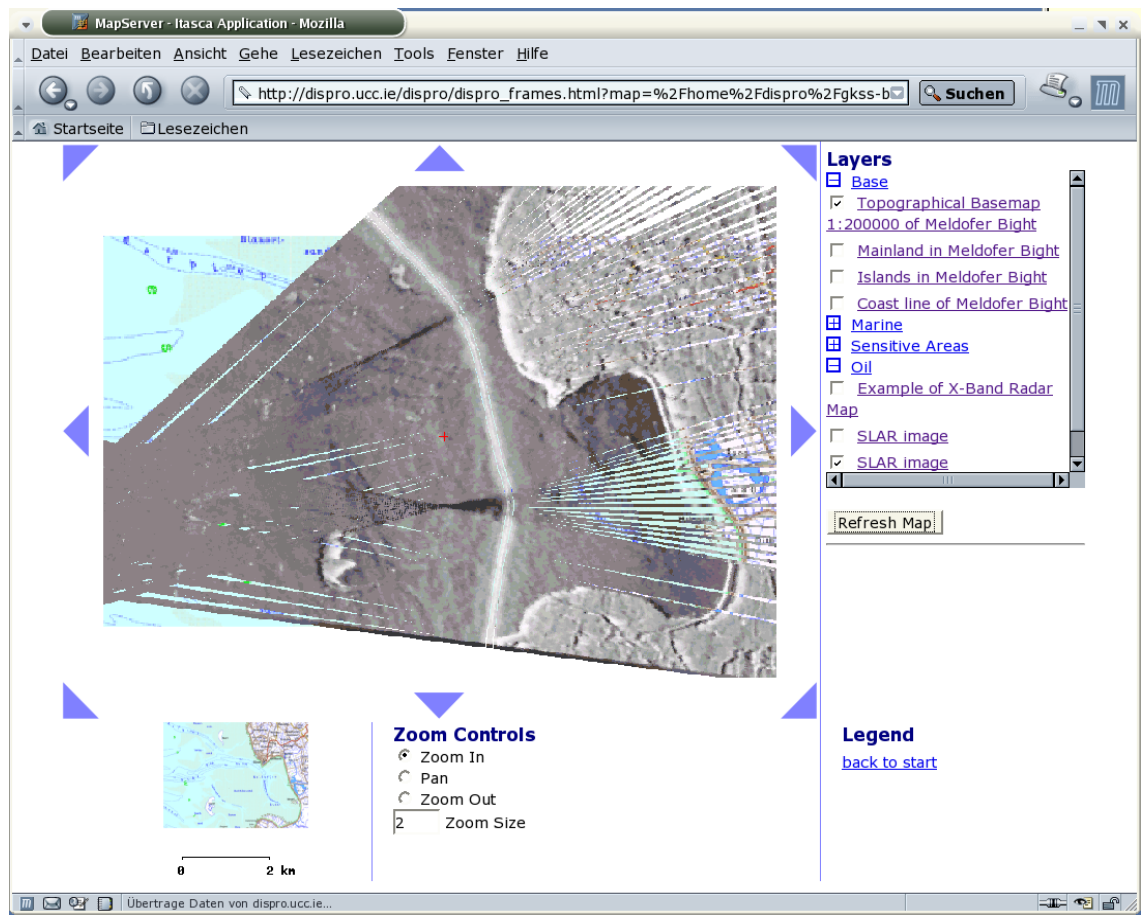

Figure 6: Screenshot of a web map server interface showing a geo-referenced SLAR image (Robbe and Hengstermann [12]).

\section{Concluding remarks}

At present, there are many well-established oil spill remote sensing techniques like IR/UV line scanning, microwave radiometry, laser fluorosensing, and side-looking airborne radar. The MEDUSA network is a system for continuous acquisition of 
arbitrary types of oil spill data which are remotely sensed from airborne platforms. The features of the MEDUSA software module for analysis and fusion of oil spill data are spatial analysis, volume calculation, oil classification, geo-referencing, data fusion and report generation. Geo-referenced data can be exported and distributed using web-based geographical information systems (web-based GIS), a modern aspect in distributed marine crisis management.

\section{References}

[1] Fontanel, A. \& Roussel, A., La détection des nappes d'hydrocarbures sur la mer. Oceanis, 4, pp. 673-691, 1979.

[2] Robbe, N., Airborne Oil Spill Remote Sensing: Modelling, Analysis and Fusion of Multi-spectral Data. Ph.D. thesis, Institute of Experimental Physics, University of Hamburg, 2005.

[3] Fingas, M.F. \& Brown, C.E., Review of Oil Spill Remote Sensing. Spill Science \& Technology Bulletin, 4(4), pp. 199-208, 1997.

[4] Robbe, N. \& Zielinski, O., Airborne remote sensing of oil spills - analysis and fusion of multi-spectral near-range data. Journal of Marine Science and Environment, (C2), 2004.

[5] Ulaby, F.T., Moore, R.K. \& Fung, A.K., Microwave Remote Sensing: Active and Passive, volume III. Artech House, 1986.

[6] Fantasia, J.F., Hard, T.M. \& Ingrao, H.C., An investigation of oil fluorescence as a technique for the remote sensing of oil spills. Technical report, DOT/Transportation Systems Center U.S. Coast Guard, 1971. Report TSCUSCG-71-7.

[7] Hengstermann, T. \& Reuter, R., Lidar fluorosensing of mineral oil spills on the sea surface. Applied Optics, 29(22), pp. 3218-3227, 1990.

[8] Hengstermann, T., Untersuchungen zur Laserfernerkundung mariner Ölverschmutzungen. Ph.D. thesis, Department of Physics, University of Oldenburg, 1992.

[9] Hoge, F.E. \& Swift, R.N., Oil film thickness measurement using airborne laser-induced water raman backscatter. Applied Optics, 19(19), pp. 3269 3281, 1980.

[10] Garbrecht, T., Herber, A., Steinhage, D. \& Zielinski, O., Sensor network for polar research aircraft. Mem. Natl Inst. Polar Res., Spec. Issue, 59, pp. 127133, 2006.

[11] Hengstermann, T., Cembella, B., Robbe, N. \& Zielinski, O., MEDUSAnetwork for airborne and in-water operational and scientific data acquisition. Proceedings of the 8th Int. Conf. on Remote Sensing for Marine and Coastal Environments, Halifax, Canada, 2006.

[12] Robbe, N. \& Hengstermann, T., Multi-sensor data processing and distributed marine crisis management in airborne oil spill remote sensing. Proceedings of the Offshore Arabia 2006 Conference, Dubai, United Arab Emirates, 2006, in press. 